\title{
"Don't touch" bone lesions: how can we contribute?
}

\section{Francisco Abaeté das Chagas-Neto $^{1}$}

The so-called "don't touch" bone lesions are typically identified as incidental findings on imaging exams. Most of these lesions are pseudotumors, benign bone lesions or anatomical variants.

As the name suggests, "don't touch" lesions do not require the use of biopsy or other invasive procedures. However, they can be misdiagnosed as aggressive neoplastic lesions, generating concern and leading to unnecessary procedures. Correct identification of these lesions, with a specific diagnosis, minimizes the morbidity and costs associated with their management $^{(\mathbf{1})}$.

In most cases, the method used for the initial identification, characterization, and classification of "don't touch" lesions is conventional X-ray. The integrated analysis between the imaging findings and the clinical and laboratory data is essential ${ }^{(2)}$.

In some challenging situations, including uncommon presentations such as a hemophilic pseudotumor, computed tomography or magnetic resonance imaging can be used in order to characterize the lesion, thus increasing the reliability and confidence in the accuracy of the diagnosis ${ }^{(3-6)}$.

There is currently a tendency to use computerized systems to support the clinical decision and diagnosis, contributing to the management of medical knowledge. In a recent article addressing this theme, Moreira et al. ${ }^{(7)}$ described a cognitive mapping system specifically focused on supporting the diagnosis of solitary bone tumors in pediatric patients, with the objective of supporting the decisions of medical professionals and promoting training in the area, potentially reducing errors in the diagnosis of such lesions. Costa ${ }^{(\mathbf{8})}$ also recently discussed the application of artificial intelligence in the evaluation of bone tumors, highlighting the great potential of such tools. However, the au-

1. PhD, Professor of Radiology at the Centro Universitário Christus, Fortaleza, CE, Brazil. Email: fabaeteneto@gmail.com. https://orcid.org/0000-0002-6987-2072. thor emphasized the importance of face-to-face physician-patient interaction in the overall approach to cancer patients.

In an article published in this issue of Radiologia Brasileira, Fonseca et al. ${ }^{(9)}$ have reviewed, in an illustrative way, the main bone pseudotumors and "don't touch" lesions. The authors addressed a variety of such lesions/conditions-cortical desmoids, subchondral cysts, costochondritis, small bone islands, fibrous dysplasia, non-ossifying fibromas, simple bone cysts, aneurysmal bone cysts, bone infarction, synovial cysts, melorheostosis, vertebral hemangiomas, discogenic vertebral sclerosis, myositis ossificans, and humeral pseudocysts-, highlighting their main characteristics on the various imaging methods.

Radiologists and radiology residents need to be familiar with the "don't touch" lesions and their different presentations in the various imaging methods. Thus, they can actively and efficiently contribute to the diagnosis and follow-up of these patients, avoiding unnecessary invasive procedures, reducing patient morbidity, and optimizing the use of health care resources.

\section{REFERENCES}

1. Gould CF, Ly JQ, Lattin GE Jr, et al. Bone tumor mimics: avoiding misdiagnosis. Curr Probl Diagn Radiol. 2007;36:124-41.

2. Andrade Neto F, Teixeira MJD, Araújo LHC, et al. Knee bone tumors: findings on conventional radiology. Radiol Bras. 2016; 49:182-9.

3. Koenigkam-Santos M, Polezi MB, Engel EE, et al. Uncommon presentations of intraosseous hemophilic pseudotumor in imaging diagnosis. Radiol Bras. 2009; 42:159-63.

4. Nogueira-Barbosa MH, Sá JL, Trad CS, et al. Magnetic resonance imaging in the evaluation of periosteal reactions. Radiol Bras. 2010;43:266-71.

5. Sá Neto JL, Simão MN, Crema MD, et al. Diagnostic performance of magnetic resonance imaging in the assessment of periosteal reactions in bone sarcomas using conventional radiography as the reference. Radiol Bras. 2017;50:176-81.

6. Aihara AY. Imaging evaluation of bone tumors. Radiol Bras. 2016;49(3):vii.

7. Moreira FC, Aihara AY, Lederman HM, et al. Cognitive map to support the diagnosis of solitary bone tumors in pediatric patients. Radiol Bras. 2018;51:297-302.

8. Costa FM. Evaluation of musculoskeletal tumors in the new era of artificial intelligence. Radiol Bras 2018;51(6):ix-x.

9. Fonseca EKUN, Castro AA, Kubo RS, et al. Lesões musculoesqueléticas do tipo "não toque": ensaio iconográfico. Radiol Bras. 2019;52:48-53.

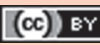

